\title{
Exercise plus diet improved cholesterol concentrations in high risk adults
}

Stefanick ML, Mackey S, Sheehan M, et al. Effects of diet and exercise in men and postmenopausal women with low levels of HDL cholesterol and high levels of LDL cholesterol. N Engl J Med 1998 Jul 2;339:12-20.

\begin{abstract}
Question
Can diet (National Cholesterol Education Program [NCEP] recommended diet), exercise, or both improve the lipid profiles of men and women with low concentrations of high density lipoprotein (HDL) cholesterol and high concentrations of low density lipoprotein (LDL) cholesterol?
\end{abstract}

\section{Design}

Randomised controlled trial with 12 months follow up (Diet and Exercise for Elevated Risk trial).

\section{Setting}

A community based study in California, USA.

\section{Patients}

180 postmenopausal women and 197 men. Women were $45-64$ years old, had HDL cholesterol concentrations $<1.55 \mathrm{mmol} / \mathrm{l}$ $(60 \mathrm{mg} / \mathrm{dl})$, and LDL cholesterol concentrations from $>3.23-$ $5.42 \mathrm{mmol} / \mathrm{l}(>125-209 \mathrm{mg} / \mathrm{dl})$. Men were $30-64$ years old, had HDL cholesterol concentrations $<1.14 \mathrm{mmol} / \mathrm{l}(45 \mathrm{mg} / \mathrm{dl})$, and LDL cholesterol concentrations $>3.23-4.90 \mathrm{mmol} / \mathrm{l}$ (>125-189 mg/dl). Exclusion criteria were history of cardiovascular disease, diabetes, or other severe illness; treatment with insulin, cardiac medications, or cholesterol or blood pressure lowering drugs; smoking; high alcohol consumption; high blood glucose or triglyceride concentrations; or high body mass index. Follow up was $97 \%$.

\section{Intervention}

Participants were allocated to diet alone (47 women and 49 men), exercise alone (44 women and $50 \mathrm{men}$ ), diet and exercise (43 women and $51 \mathrm{men}$ ), or neither (46 women and 47 men). The diet programme was the NCEP Step $2 \operatorname{diet}(<30 \%$ total fat,
$<7 \%$ saturated fat, and $<200 \mathrm{mg}$ of cholesterol/d) initiated by a dietitian using an individual session and 8 group sessions during a 12 week adoption phase and monthly follow up. The aerobic exercise programme included an individual session and group sessions during a 6 week adoption phase and a 7-8 month maintenance phase. Exercise was 3 times/week and equivalent to brisk walking or jogging for $16 \mathrm{~km} /$ week (10 mi).

\section{Main outcome measures}

Differences in dietary intake and lipoprotein concentrations.

\begin{abstract}
Main results
The diet and diet plus exercise groups reduced their intake of calories, fats (saturated, monounsaturated, and total fats), and cholesterol; increased their intake of carbohydrates; and reduced their body weight. The 2 exercise groups had improved exercise capacity. Total cholesterol and LDL cholesterol concentrations were reduced in the diet plus exercise group but not in the diet alone or exercise alone groups in both women and men. HDL cholesterol and triglyceride concentrations did not change in any group; $\mathrm{p} \leqslant 0.05$ for all comparisons.
\end{abstract}

\section{Conclusions}

Diet plus exercise reduced total and LDL cholesterol concentrations in women and men with low HDL and high LDL cholesterol concentrations at baseline. Neither diet alone nor exercise alone improved the overall lipid profile.

Source of funding: National Heart, Lung, and Blood Institute.

For correspondence: Dr M L Stefanick, 730 Welch Road, Suite B, Palo Alto, CA 94304-1583, USA. Fax +16507237018

A modified version of this abstract appears in ACP Journal Club.

\section{Commentary}

The risk factors associated with heart disease are well known. We need to focus on interventions to reduce the risk of heart disease as we facilitate and sometimes rationalise the need for lifestyle change. In earlier studies, Stefanick et al found that weight loss increased HDL cholesterol concentrations (the beneficial type of cholesterol), ${ }^{1}$ and that physical activity prevented the reduction of HDL cholesterol concentrations ${ }^{2}$ that often results from a low fat diet. In their 1991 study, they found that an NCEP Step 1 diet did not reduce LDL cholesterol concentrations (a potentially harmful type of cholesterol) in men, with or without exercise, but did reduce LDL cholesterol concentrations in premenopausal women. ${ }^{2}$

When women are diagnosed with cardiac disease, they tend to be diagnosed with chronic disease, whereas men are usually diagnosed with acute disease. Therefore, interventions aimed at making long term lifestyle changes in women are especially important. A limitation of this study was that it did not include women $>65$ years of age, a group in which the incidence of cardiac disease dramatically increases. $^{2}$

This randomised controlled trial is strong because of the large sample size and because the results add to those of previous studies. It showed primarily that diet plus exercise was effective in reducing total and LDL cholesterol concentrations for both sexes with low baseline HDL and high LDL cholesterol concentrations. Patients who are at risk and who are willing to add exercise to a reduced fat diet may not have to use medication. The results need to be stressed-neither diet alone nor exercise alone improved lipid profiles.

From a clinical perspective, I wonder if the results would differ with a higher level of exercise (this sample averaged about 16 $\mathrm{km} / \mathrm{wk}$ of jogging or brisk walking) and weight reduction because triglycerides often decrease with weight loss, and HDL cholesterol concentrations generally increase with exercise and weight loss. ${ }^{3}$ Both long term weight loss and increased exercise are hard to achieve and require intensive intervention and follow up. This study lasted 1 year. Getting patients to participate and maintain lifestyle changes will always be a challenge. I plan to share this research with my patients. The results can certainly add to quality of life and who does not want that?

Kathy James, NP, DNSc Assistant Professor of Nursing University of San Diego

School of Nursing and Health Sciences San Diego, California, USA

1 Wood PD, Stefanick ML, Dreon DM, et al. $N$ Engl J Med 1998;319:1173-9.

2 Wood PD, Stefanick ML, Williams PT, et al. N Engl J Med 1991;325:461-6.

3 Dattilo AM, Kris-Etherton PM. Am J Clin Nutr 1992;56:320-8. 